members. In due course the Association, which is, of course, essentially non-profit making, will progress towards the establishment and acceptance of suitable qualifications for corrosion engineers, and the promotion of standardization in the terminology and techniques of corrosion control. When the Association is in full operation it is intended to hold full-scale meetings with papers, films and discussions, which should be of great benefit to the corrosion engineering profession as a whole and which will promote and foster its growth and development as well as being of general service to industry. Further information can be obtained from the Hon. Secretary, British Association of Corrosion Engineers, 97 Old Brompton Road, London, S.W.7.

\section{The Average Length of Working Life}

FIGURES showing the average expectation of working life for males in Great Britain, which have been prepared by the Ministry of Labour and National Service, ar 3 set out in a booklet called "The Length of Working Life of Males in Great Britain" (pp. 24. London: H.M. Stationery Office, 1959. 3s. $6 d$. net). The publication contains tables and charts which are designed to provide answers to questions like: How many years on the average can men of a given age expect to continue at work? What proportion of the men of a given age in the working population can expect to be still working at sixty-five and then have a period of retirement? What were the estimated losses from the working population in 1955 owing to death and retirements ? For example, the 1955 table shows that on the average boys aged fifteen can expect to have 48.4 years in the working population. Of the men aged thirty in the working population, 62 per cent can expect to be still in the working population at age sixty-five. For those men aged sixty-five in the working population, 75 per cent can expect to retire at some later age. A very large population (31 per cent) can expect to retire before reaching their sixtysixth birthday. A comparison between 1931 and 1955 shows that over this period the expectation of working life at birth rose from 40.6 years-an increase of $12 \frac{1}{2}$ per cent. This was entirely due to the reduction in mortality-rates, which outweighed the effect of the raising of the school-leaving age and of the movement to earlier retirement. There is a growing demand for the kind of information given in these tables because private pension schemes and the new social security legislation introduced into Britain during the present century have made it possible for an increasing number of people to spend a significant number of years in retirement. 'Probability of survival' tables have been in use for a long time, but since there is now a substantial difference at particular years of age between the average expectation of life and the average expectation of remaining in the working population, separate tables show the expectation of working life.

\section{Training for Skill}

"Training for Skill", by Lady Gertrude Williams, issued as No. 205 in the Fabian Research Series (pp. 28. London: Fabian Society, 1959. 2s.), is based on the factual information regarding boy apprentices collected in a survey, "Recruitment to Skilled 'Trades" (see Nature, 181, 373; 1958). It also covers the Carr report, "Training for Skill", which is criticized for failing to face the profound changes in industrial structure and in public educa- tion which have made many of the traditional methods inappropriate to present needs, although the report contains an agreed criticism of the inflexibility of the present regulations. The pamphlet urges that. some new method must be found which ensures that an adequate supply of training vacancies is available to provide enough skilled workers for future needs, and that the costs of training are spread more justly over all the firms that benefit from the employment of adult skilled men. It should also ensure that men capable of learning to do a job are not permanently excluded simply because they missed the opportunity to train when they were sixteen years old, that the quality of teaching in the workshops is improved, and that the theoretical instruetion is graded to suit the capacities of the pupil. Lady Williams refers to some schemes for group training recently instituted and an extension of the 'sandwich system' as possibilities to be explored, and also suggests that apprenticeship might come to be regarded more definitely as a function of education rather than of industry. In an introduction in which she discusses industry's present needs and the limits of mass production, Lady Williams stresses the real danger that there will not be sufficient skilled workers available to understand and execute the instructions of the increased number of scientific advisers and technologists in industry.

\section{Technics and Purpose}

Two additional booklets have been announced in the admirable series launched to examine the issues arising out of the growing importance of scientific techniques in society, the rapid expansion of technological and other education and the purposes and values involved in the light of the Christian faith. The first (On Being a Technologist. Technics and Purpose, No. 5. Pp. 33. S.C.M. Press, Ltd., London, 1959. 2s. 6d. net), by Prof. D. G. Christopherson (Imperial College of Science and Technology, London), suggests that, contrary to all the pessimistic views of the persuasive advocates of 'Admass', the total responsibility shared by the members of an industrial society has increased. Once this belief is accepted it calls for a large extension of the attitude of mind formerly associated with the professions; many more people will have to make judgments based on knowledge and reason. Such a society will become increasingly individual and less amenable to the techniques of mass suggestions.

The second (The Educated Man Today and Tomorrow. Technics and Purpose, No. 6. Pp. 26. S.C.M. Press, Ltd., London, 1959. 2s. 6d. net), by Sir John Wolfenden, is noteworthy not only because it paints a clear picture of an educated man but also because it does so without becoming trite, or condescending. Besides those qualities of character which are the hallmarks of education, Sir John believes that the educated man will accept his place in the world of Nature and will see that he understands what the scientists and technologists are doing, the nature of their thinking, and, as their numbers and influence are continually increasing, the way in which they should be educated. The third requisite for an educated man put forward by Sir John shows a remarkable likeness to that advocated by Prof. Christopherson, albeit arrived at from a different approach. Prof. Christopherson writes, "Somehow or other, if a man is to do a proper job he must find means of continuing the process of education through his whole professional 